\title{
Aplicação dos silsesquioxanos dicarboxilatos de cadeia longa derivados do precursor dicatiônico bis(3-N-propiltrihidroxisilil)- 1,4 diazoniabiciclo como filmes protetores para metais
}

\author{
A.B.QUEVEDO ${ }^{1}$, G.B. MACHADO ${ }^{2,3}$, G. SCHRADER ${ }^{1}$, E.V. BENVENUTTI ${ }^{2}$, \\ T.M.H.COSTA ${ }^{2}$ \\ ${ }^{1}$ Universidade Federal do Rio Grande do Sul, Faculdade de Engenharia Química \\ ${ }^{2}$ Universidade Federal do Rio Grande do Sul, Instituto de Química \\ ${ }^{3}$ Colégio Militar de Porto Alegre \\ E-mail para contato: antonio.b280@yahoo.com.br
}

RESUMO - Este trabalho apresenta um estudo sobre a capacidade protetora de filmes híbridos preparados a partir de silsesquioxanos dicarboxilatos de cadeia longa (estearato, oleato e linoleato) quando aplicados para revestir os metais cobre e alumínio imersos em solução contendo 0,05 mol.L $\mathrm{L}^{-1} \mathrm{NaCl}$. Utilizando a técnica de espectroscopia de impedância eletroquímica (EIE) foi possível determinar que lâminas de alumínio revestidas com filmes preparados usando os silsesquioxanos dicarboxilatos, obtiveram melhores resultados contra a corrosão quando comparadas à liga nua. No caso do cobre a proteção não foi tão efetiva. Desta maneira, estes filmes híbridos sintetizados pelo método de sol-gel, com ou sem adição de trisecbutoxido de alumínio dispersa na solução inicial, permitem a formação de revestimentos anticorrosivos.

\section{INTRODUÇÃO}

Nas últimas décadas, com o avanço da tecnologia, a exigência por novos materiais com propriedades controladas aumentou. Desta forma, surgiu o ramo de pesquisa dos materiais híbridos organo-inorgânicos, que devido ao tamanho reduzido dos domínios que os compõe e do grande número de átomos em interfaces, possuem propriedades diferenciadas conforme Benvenutti et al (2009). Esses materiais podem ser produzidos a partir do método sol-gel de síntese, e a baixa temperatura das reações permite a inserção satisfatória de grupos orgânicos em sistemas inorgânicos. O método sol-gel se baseia na hidrólise e policondensação de precursores óxidos, alcóxidos ou organossilanos. Forma-se primeiramente um sol e em seguida um gel. Após, é feita a evaporação cuidadosa do gel em condições ambiente. Durante esse processo a estrutura do gel é profundamente modificada, havendo uma contração no volume do gel com diminuição da área superficial e do volume dos poros formando um sólido de estrutura peculiar, chamado xerogel. O método sol-gel permite a preparação de pós, filmes, monólitos.

Em trabalhos anteriores de Arenas et al (2006 e 2008) foi preparado em nosso laboratório um novo precursor organossilano para ser usado no método sol-gel foi sintetizado, o dicloreto de 3-npropiltrimetoxisilil-1,4-diazôniabiciclo [2, 2, 2] octano (dicloreto de dabco precursor) contendo o grupo orgânico ligado em ponte. Após a hidrólise do precursor, formase o dicloreto de bis (3-n-propiltrihidróxisilil)-1,4 diazôniabiciclo (dicloreto de dabco 


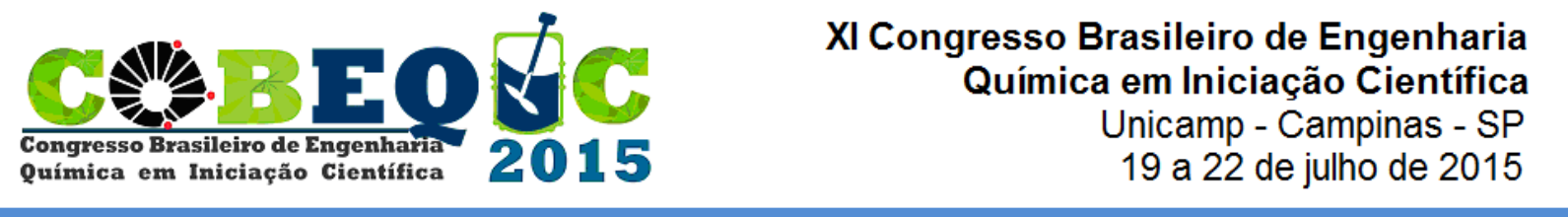

hidrolisado), um silsesquioxano dicatiônico. Por troca iônica do cloreto com ânions carboxilatos de cadeia longa o dicloreto de dabco hidrolisado forma os compostos utilizados no presente trabalho, diestearato de dabco, dioleato de dabco e dilinoleato de dabco, chamados de silsesquioxanos dicarboxilatos, sendo mostrada na Figura 1 uma reação típica de troca iônica. A inserção de cadeias longas carbônicas nos compostos aumenta o seu grau de hidrofobicidade e consequentemente modifica as propriedades do composto ampliando suas aplicações de acordo com Silva et al (2012).

Figura 1- Equação de síntese por troca iônica de diestearato de bis(3-n-propiltrihidroxisilil)1,4 diazoniabiciclo[2,2,2]octano.

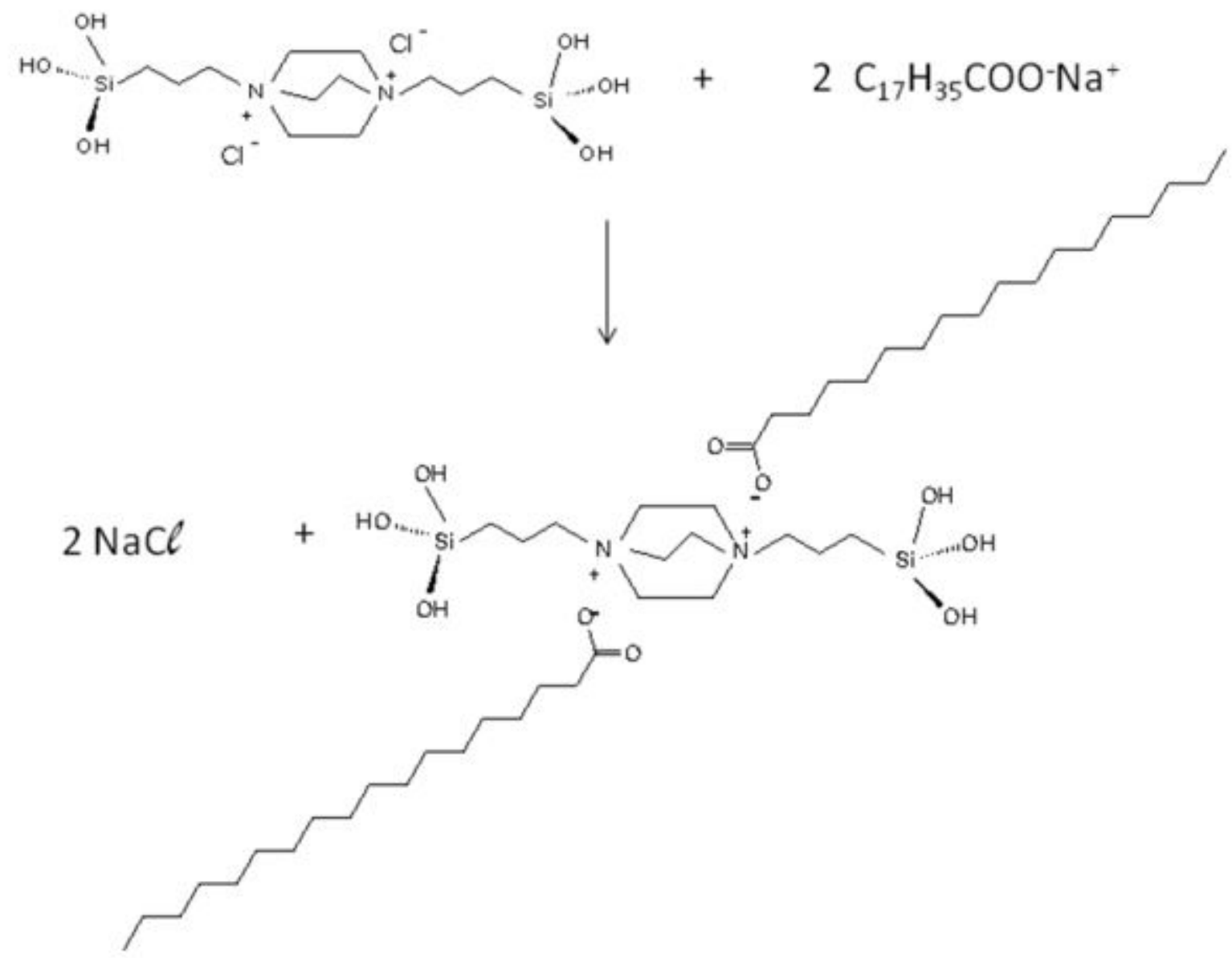

\subsection{Metodologia e Resultados}

Foram preparadas soluções contendo os silsesquioxanos dicarboxilatos em n-butanol, mostradas na Figura 2 e, após a limpeza foram cortadas lâminas de aproximadamente $0,02 \mathrm{~m} \mathrm{x}$ $0,03 \mathrm{~m}$ das placas de metal, como mostrado na Figura 3. A deposição do filme foi feita pelo método "dip coating" com duas imersões das lâminas dos metais na solução durante 5 minutos e cura em estufa durante $1 \mathrm{~h}$ a $70^{\circ} \mathrm{C}$ entre cada imersão. As lâminas então, já com os filmes depositados, são revestidas com resina acrílica de forma que apenas uma área de aproximadamente $1 \mathrm{~cm}^{2}$ é deixada exposta, como mostra a Figura 4, para que possam ser feitos os testes de EIE. Foi feita a investigação da capacidade anticorrosiva dos filmes 


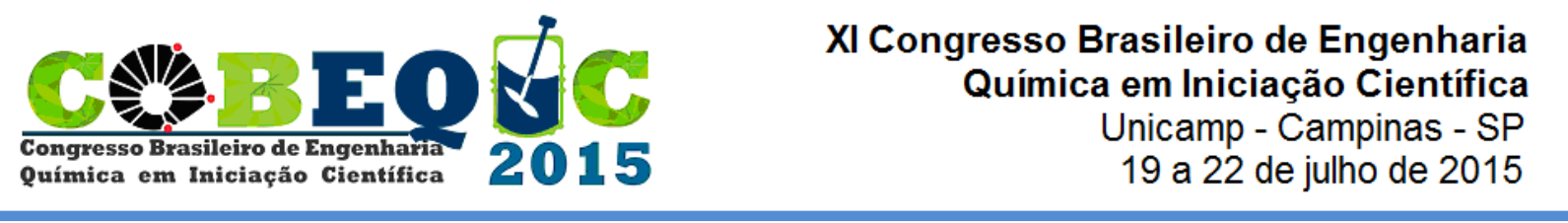

híbridos quando revestindo os metais cobre e alumínio sendo utilizados três tipos de silsesquioxanos dicarboxilatos sintetizados para preparar os filmes.

Figura 2-Soluções de silsesquioxanos dicarboxilatos com n-butanol

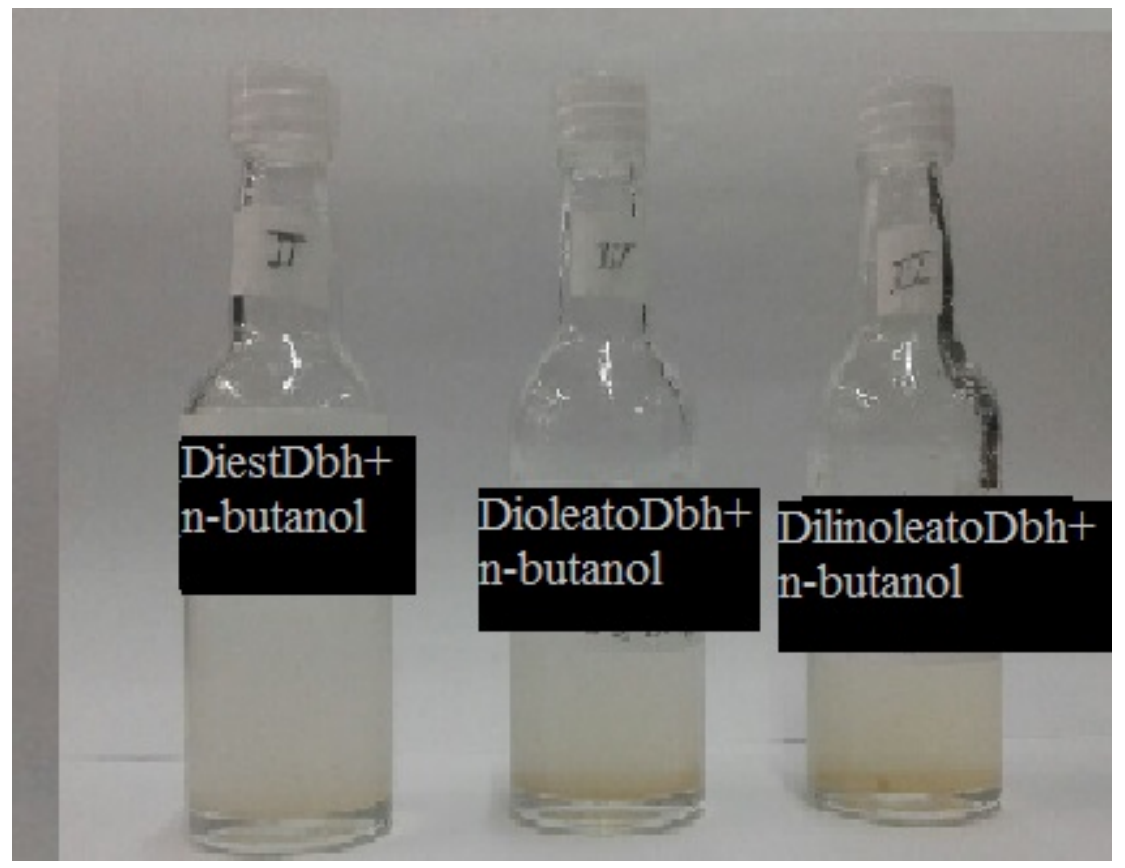

Figura 3 - Placa de cobre cortada em $0,02 \mathrm{~m}$ x 0,03m

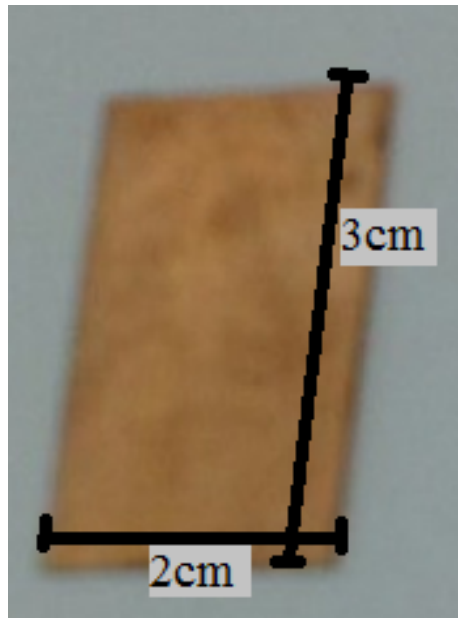


Figura 4 - Lâmina de cobre já revestida com o filme e revestida com resina acrílica, com área de aproximadamente $1 \mathrm{~cm}^{2}$ exposta.

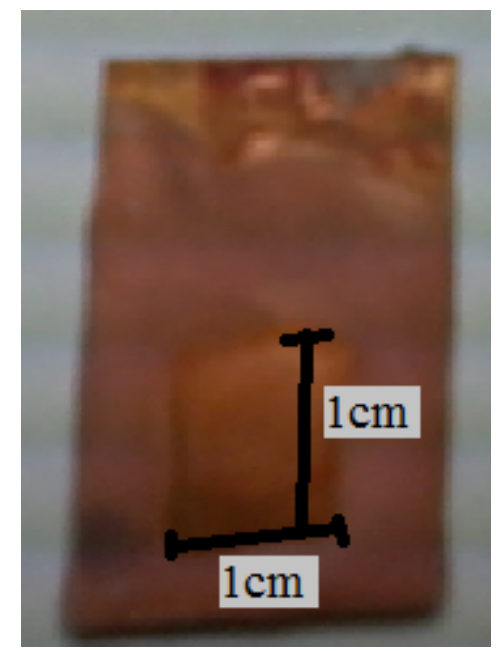

É sabido que o ângulo de fase, obtido no presente trabalho a partir do diagrama de bode, onde relaciona a parte real da impedância e o ângulo de fase com a frequência, em escalas logarítmicas, é tanto maior quanto maior for a barreira de proteção e a resistência associada ao circuito do sistema. Sendo assim, a comparação feita na Tabela 1 entre o ângulo de fase do cobre revestido com os filmes preparados com os silsesquioxanos dicarboxilatos com adição de trisecbutoxido de alumínio ou não, frente à liga nua, nos mostra a capacidade protetora destes materiais híbridos. O ângulo de fase da liga nua atinge valores máximos de $56^{\circ}$, enquanto o ângulo de fase do cobre revestido com os filmes atinge valores máximos de $56,8^{\circ}$ para o dilinoleato, $65,4^{\circ}$ para o dioleato e $64,5^{\circ}$ para o diestearato.

Tabela 1 - Comparação entre liga nua de cobre e liga de cobre revestida com filmes preparados a partir de silsesquioxanos dicarboxilatos, quando imersos em solução corrosiva de $0,05 \mathrm{~mol} . \mathrm{L}^{-'} \mathrm{NaCl}$ durante $72 \mathrm{~h}$.

\begin{tabular}{|c|c|c|c|c|}
\hline & $\begin{array}{c}\text { Liga } \\
\text { nua de } \\
\text { cobre }\end{array}$ & $\begin{array}{c}\text { DilinoleatoDbh+ } \\
\text { n-butanol }\end{array}$ & $\begin{array}{c}\text { DioleatoDbh+ } \\
\text { n-butanol }\end{array}$ & $\begin{array}{c}\text { DiestDbh+ } \\
\text { n-butanol }\end{array}$ \\
\hline $\begin{array}{c}\text { Ângulo } \\
\text { de fase }\end{array}$ & $\mathbf{5 6}^{\mathbf{0}}$ & $\mathbf{5 6 , 8}^{\circ}$ & $\mathbf{6 5 , 4 ^ { \circ }}$ & $\mathbf{6 4 , 5}^{\mathbf{0}}$ \\
\hline
\end{tabular}

Quando testada, a liga nua de alumínio atinge valores máximos de ângulo de fase em torno de $58^{\circ}$, enquanto a liga revestida com os filmes atinge valores de $76^{\circ}$ para o dilinoleato, $70^{\circ}$ para o dioleato e $79^{\circ}$ para o diestearato, todas as soluções com trisecbutoxido de alumínio disperso, comparação mostrada na Tabela 2. Esta melhora ocorre porque a dispersão do trisecbutóxido de alumínio na formação do filme aumenta a porção inorgânica e a presença dos silsesquioxanos dicarboxilatos aumenta a proporção apolar do composto, aumentando assim o grau de hidrofobicidade. A presença dos componentes inorgânicos causa uma maior adesão do filme à placa de metal. 


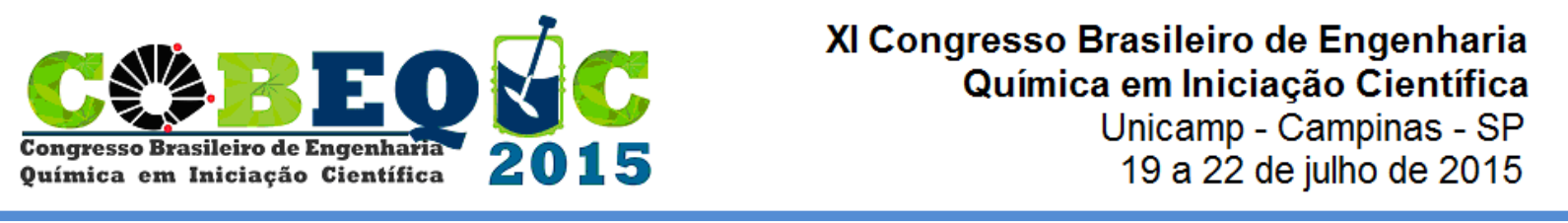

Tabela 2 - Comparação entre liga nua de alumínio e liga de alumínio revestida com filmes preparados a partir de silsesquioxanos carboxilatos com adição de trisecbutoxido de alumínio, quando imersos em solução corrosiva $0,05 \mathrm{~mol} . \mathrm{L}^{-'} \mathrm{NaCl}$ durante 72 horas.

\begin{tabular}{|l|c|c|c|c|}
\hline & $\begin{array}{c}\text { Liga nua de } \\
\text { alumínio }\end{array}$ & $\begin{array}{c}\text { DilinoleatoDbh+ } \\
\text { trisecbutAl+ } \\
\text { n-butanol }\end{array}$ & $\begin{array}{c}\text { DioleatoDbh+ } \\
\text { trisecbutAl+ } \\
\text { n-butanol }\end{array}$ & $\begin{array}{c}\text { DiestDbh+ } \\
\text { trisecbutAl+ } \\
\text { n-butanol }\end{array}$ \\
\hline Ângulo de fase & ${58^{\circ}}^{\circ}$ & $\mathbf{7 6}^{\circ}$ & $\mathbf{7 0}^{\circ}$ & $\mathbf{7 9}^{\circ}$ \\
\hline
\end{tabular}

Conclusão: Os estudos apresentados sugerem uma capacidade protetora eficiente dos filmes preparados a partir de silsesquioxanos dicarboxilatos revestindo o metal alumínio, porém, quando revestindo o metal cobre, não se mostram tão efetivos. Esse resultado pode demonstrar que a adesão dos filmes ao metal é maior no caso do alumínio. Em trabalhos anteriores observou-se que esses silsesquioxanos iônicos apresentam uma afinidade por superfícies de alumínio ou óxido de alumínio.

\section{REFERÊNCIAS}

ARENAS, L.T.; PINHEIRO, A.C.; FERREIRA, F.D.; LIVOTTO, P.R.; PEREIRA, V.P.; GALLAS, M.R.; GUSHIKEM, Y.; COSTA, T.M.H.; BENVENUTTI, E.V.; J. Colloid Interface Sci. 2008, 318, 96-102.

ARENAS, L.T.; DIAS, S.L.P.; MORO, C.C.; COSTA, T.M.H.; BENVENUTTI, E.V.; LUCHO, A.M.S.; GUSHIKEM, Y.; J. Colloid Interface Sci. 2006, 297, 244-250.

BENVENUTTI, E.V.; MORO, C.C; COSTA, T.M.H.; GALlAS, M.R.; Quím. Nova, 2009, 32, 1926-1933..

SILVA, P.R.; ALMEIDA, V.O.; MACHADO, G.B.; BENVENUTTI, E.V.; COSTA, T.M.H.; GALLAS, M.R.; Langmuir 2012, 28, 1447-1452. 